University of Massachusetts Amherst

From the SelectedWorks of Julian Tyson

1986

\title{
A Microcomputer-Based Peak-Width Method of Extended Calibration for Flow-Injection Atomic Absorption Spectrometry
}

Julian Tyson

Stephen Bysouth, Loughborough University of Technology 


\title{
A MICROCOMPUTER-BASED PEAK-WIDTH METHOD OF EXTENDED CALIBRATION FOR FLOW-INJECTION ATOMIC ABSORPTION SPECTROMETRY
}

\author{
STEPHEN R. BYSOUTH and JULIAN F. TYSON* \\ Department of Chemistry, University of Technology, Loughborough, Leicestershire, \\ LE11 $3 T U$ (Great Britain)
}

(Received 21st August 1985)

Summary. In the proposed method of extended calibration based on peak widths, all data collection and reduction are done by a microcomputer interfaced to the spectrometer. The method produces an estimate of concentration without dilution of the off-range samples. Calibrations covering the ranges $40-1000 \mathrm{mg} \mathrm{l}^{-1}, 1.0-50 \mathrm{mg} \mathrm{l}^{-1}$ and $20-1000$ $\mathrm{mg} \mathrm{l}^{-1}$ were obtained for chromium, magnesium and nickel, respectively.

The feasibility of using a peak-width calibration method to calculate offrange concentrations by injection of samples close to the nebulizer of a flowinjection system with an atomic absorption spectrometric detector has been demonstrated by Tyson [1], who derived an equation relating peak width to the concentration injected, according to the "single well-stirred mixing chamber" model [2]. Stewart and Rosenfeld [3] incorporated a real mixing chamber into a flow-injection system and used an equation derived by Pardue and Fields $[4,5]$ for flow-injection titrations, to provide an extended calibration. The derivation is complex, and in its application to calibration, some unnecessary simplifications were made. This produced an equation where peak width is proportional to the logarithm of the concentration injected, whereas if no approximations are made in deriving the equation [1], this is not the case. Both groups of workers measured the peak widths at one concentration level on the peak profile and produced linear calibration graphs, thus demonstrating the validity of the relationships. In this communication, results obtained by using a microcomputer for data acquisition and processing are presented. The calibrations were generated from the widths at several concentration levels on the peak profiles.

\section{Experimental}

Solutions. Standards containing chromium, nickel or magnesium were made by serial dilution of $1000 \mathrm{mg} \mathrm{l}^{-1}$ stock solutions (BDH Chemicals or Fisons).

Equipment. A Baird-Atomic A3400 spectrometer with an air/acetylene flame was optimized for maximum sensitivity for each element. 
The manifold (Fig. 1) consisted of a pneumatically operated injection valve (P.S. Analytical, T-series), a peristaltic pump (Ismatec 840) and a streamswitching valve (Pharmacia). The connection between the injection valve and nebulizer was $2 \mathrm{~cm}$ of teflon tubing $(0.71 \mathrm{~mm}$ i.d.; Radio Spares, number 1$)$. The flow rate used was $4.7 \mathrm{ml} \mathrm{min}^{-1}$ and the volume injected was $82.3 \mu \mathrm{l}$.

Interface and microcomputer. The chart recorder output of the spectrometer was connected to an Apple IIe microcomputer via an A/D converter (Micro-Control) and a signal-conditioning unit built in this laboratory. This unit allowed signal offset if required. Time values were read from a clock card (Mountain Hardware). The program was written in BASIC; copies are available from the authors on request.

Data acquisition. Thirty readings were made for all steady states (i.e., baseline and normally aspirated standards), the baseline being read before normal calibration and before injection of concentrated standards or samples. Three hundred time and absorbance data points were collected per injection at a rate of $14 \mathrm{~s}^{-1}$.

Data processing. The rational function

$A / C=a+b A+c A^{2}$

(where $A$ is absorbance, $C$ concentration and $a, b$ and $c$ are constants to be found during the curve-fitting process), was fitted to the normal calibration data points. This function [6] was found to give consistently good results in earlier work in this laboratory. Each data point consisted of the average of the thirty absorbance values collected and the corresponding concentration input from the keyboard. Curve-fitting was achieved by the method developed by Miller [7].

The 300 data points collected per injection were sorted into those containing peak information and those at the baseline level. Each absorbance on the rise portion of the peak was then matched to the closest absorbance value on the full curve. The associated times were subtracted to give the peak widths for each absorbance level. The absorbances were then converted to concentrations by using the rational function of the normal calibration. This process is summarized in Fig. 2. These values for peak width and concentration were then used, together with the concentration originally injected (entered via the keyboard), to obtain the peak width calibration function.

Initially the equation developed by Tyson [1]

$t^{\prime}=(V / u) \ln \left[\left(C_{\mathrm{m}} / C^{\prime}\right)-1\right]-(V / u) \ln (D-1)$

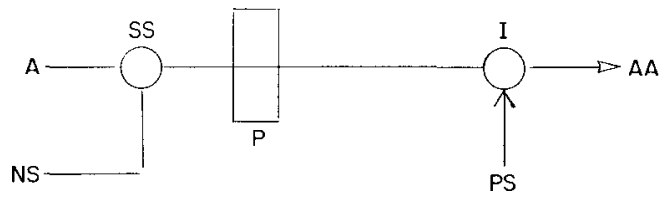

Fig. 1. Flow-injection manifold: SS, stream-switching valve; NS and PS, points where normal standards and peak-width standards are introduced, respectively; A, aqueous carrier; $P$, pump; I, injection valve; AA, spectrometer. 


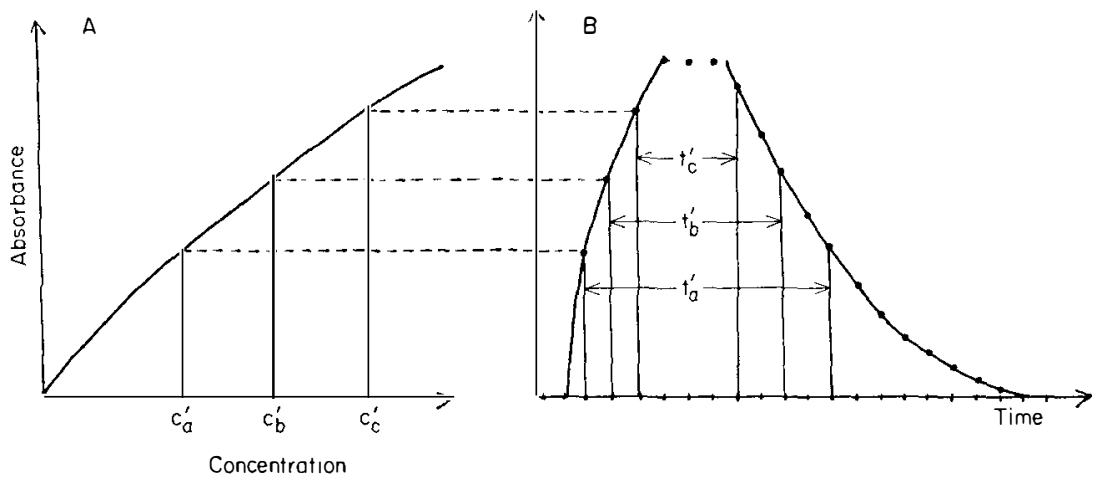

Fig. 2. Data conversion from time and absorbance to peak width and concentration: A, normal calibration; $\mathrm{B}$, recorded peak. $t_{\mathrm{a}}^{\prime}, t_{\mathrm{b}}^{\prime}$ and $t_{\mathrm{c}}^{\prime}$ are the peak widths at concentrations $C_{\mathrm{a}}^{\prime}, C_{\mathrm{b}}^{\prime}$ and $C_{\mathrm{c}}^{\prime}$ respectively, calculated from absorbance $(A)$, concentration $(C)$ and time $(t)$.

was fitted by using the least-squares procedure, as used for the normal calibration. (In Eqn. 2, $t^{\prime}$ is the width of the peak measured at a concentration $C^{\prime}, V$ the theoretical volume of the mixing chamber, $u$ the flow rate, $C_{\mathrm{m}}$ the concentration injected and $D$ the dispersion of the system.)

Plotting the calibration data $t^{\prime}$ vs. $\ln \left[\left(C_{\mathrm{m}} / C^{\prime}\right)-1\right]$ (Fig. 3) showed that the relationship was not linear as expected. A cubic function, suggested by the shape of the graph plotted, was used instead, fitted by least squares:

$t^{\prime}=d+e F+f F^{2}+g F^{3}$

where $F=\ln \left[\left(C_{\mathrm{m}} / C^{\prime}\right)-1\right]$ and $d, e, f$ and $g$ are constants to be found during the fitting procedure.

On injection of an unknown, the peak widths are transformed to $F$ values by solving for the root of Eqn. 3 using Newton's approximation method [7]. The mean concentration injected is then calculated from the $F$ values and the concentration levels $\left(C^{\prime}\right)$ at which the corresponding widths were measured.

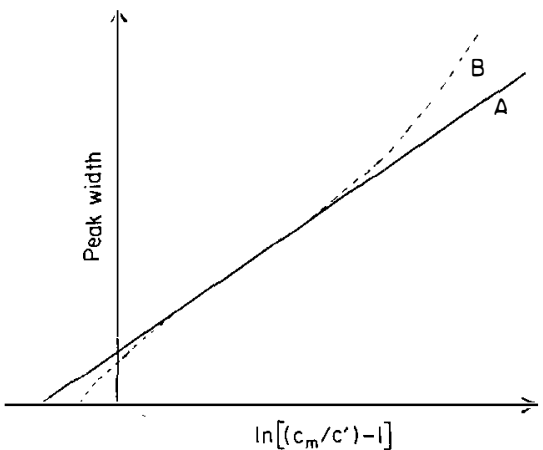

Fig. 3. Peak-width calibration curves: A, theoretical calibration line according to Eqn. 2; $\mathrm{B}$, a typical calibration curve found in these experiments. 
Procedure. The system was calibrated by aspiration of the standards for normal calibration. Valve SS (Fig. 1) was switched to the standard/sampling position, and the concentration of the standard was entered through the keyboard once steady state had been achieved. This initiated the reading cycle. The process was repeated for all the standards. Once a normal calibration had been generated, valve SS was turned again and three "peak-width" standards were injected in turn, the concentration of each being entered to initiate the read cycle. The concentrations of the five standards used for each of the normal calibrations covered the ranges $5-40 \mathrm{mg} \mathrm{l}^{-1}$. for chromium, $0.1-$ $1.0 \mathrm{mg} \mathrm{l}^{-1}$ for magnesium and $5-20 \mathrm{mg} \mathrm{l}^{-1}$ for nickel. Fitting the rational function to these calibrations gave correlation coefficients of $0.9996,0.9085$ and 0.9984 , respectively. The "peak-width" standards (Table 1) were then re-injected at least ten times as unknowns, in random order, to enable the calibration to be evaluated.

Evaluation of the calibration. The values obtained for each "unknown" were compared by using the $Q$ test [8] and any outliers were rejected. The remaining values were used to calculate the standard deviation (s.d.), relative standard deviation (r.s.d.) and the mean value together with its $95 \%$ confidence interval, for each unknown.

\section{Results and discussion}

The peak-width calibration deviates from a straight line; peaks are broader than expected at higher concentrations. This could be due to the formation of large salt clotlets at high concentrations which would be slower to vaporize in the flame, giving larger peak widths and "smaller $C^{\prime}$ values. Also, at high concentrations, the wash-out of an individual drop from the nebulizer spray chamber is readily detected as a small peak on the falling absorbance/concentration profile.

The results of the analyses are presented in Table 1. These results show about $8 \%$ r.s.d. and some bias at the $95 \%$ confidence level. Two main factors contribute to the errors in this method, namely, the goodness of fit of the calibration curve to the experimental points, and the random fluctuations in the absorbance/time profiles observed for replicate injections of the same concentration. Bias is most likely due to errors in the fit of the calibration curve. These will be increased if the instrument response drifts. The large r.s.d. values, compared with a conventional calibration procedure, are due to the logarithmic relationship between peak width and concentration. This will always be a limitation to any flow-injection peak-width method. To some extent the problem can be minimized by increasing the data acquisition rate. In the present method, the rate is $14 \mathrm{~s}^{-1}$ which is rather too slow for the rapid rise in absorbance obtained at higher concentrations, producing only a few points on the rise curve from which to calculate the average concentration.

The method has potential for use as a screening method for calculating dilution factors required to bring off-range samples within the range of the normal calibration. Dilution of such samples is usually done by time-consuming 
TABLE 1

Peak-width calibration data and results

\begin{tabular}{|c|c|c|c|c|c|c|}
\hline \multirow[t]{2}{*}{ Metal } & \multirow[t]{2}{*}{$r^{\mathbf{a}}$} & \multicolumn{3}{|c|}{ Concentrations of metal $\left(\mathrm{mg} \mathrm{l}^{-1}\right)$} & \multirow{2}{*}{$\begin{array}{l}\text { R.s.d. } \\
(\%)\end{array}$} & \multirow{2}{*}{$\begin{array}{l}95 \% \\
\text { CI }^{d}\end{array}$} \\
\hline & & $\begin{array}{l}\text { Injected } \\
\text { standards }\end{array}$ & $\begin{array}{l}\text { Calculated from peak-width } \\
\text { calibrationc }\end{array}$ & $\begin{array}{l}\text { Mean } \\
\text { calcd. }\end{array}$ & & \\
\hline \multirow[t]{3}{*}{$\mathrm{Cr}$} & 0.9969 & 1000 & $\begin{array}{l}1112,1117,1047,1155 \\
1061,1194,1201,1038, \\
943.1,1110\end{array}$ & 1098 & 7.14 & 56.1 \\
\hline & & $\because$ & $\begin{array}{l}105.9,96.94,95.95,109.7 \\
111.8,105.1,105.1,112.8 \\
107.4,110.5\end{array}$ & 106.1 & 5.44 & 4.13 \\
\hline & & : & $\begin{array}{l}41.66,37.82,34.89,39.99 \\
38.96,38.14,41.44,43.09 \\
37.17,34.4,38.10\end{array}$ & 38.70 & 7.03 & 1.95 \\
\hline \multirow[t]{3}{*}{ Mg } & 0.9981 & 50 & $\begin{array}{l}63.29,47.06,59.40,55.09 \\
55.94,60.22,75.32,48.49 \\
57.41,61.68\end{array}$ & 56.5 & 11.2 & 4.31 \\
\hline & & 10 & $\begin{array}{l}10.89,10.66,12.00, \frac{14.75}{10} \\
10.70,11.00,11.98,10.49 \\
11.66,11.03\end{array}$ & 11.16 & 5.16 & 0.443 \\
\hline & & $\begin{array}{c}1.0 \\
:\end{array}$ & $\begin{array}{l}1.082,1.146,0.9426,1.030 \\
1.077,1.055,1.050,1.082 \\
1.028,1.081\end{array}$ & 1.06 & 2.18 & $1.93 \times 10^{-2}$ \\
\hline \multirow[t]{3}{*}{$\mathrm{Ni}$} & 0.9978 & 1000 & $\begin{array}{l}1156,909.0,1118,890.4 \\
1278,938.4,906.0,1043, \\
1014,955.9\end{array}$ & 1021 & 12.6 & 91.8 \\
\hline & & 100 & $\begin{array}{l}142.8,123.1,103.4,110.6 \\
127.0,115.6,130.2,129.0 \\
88.93,121.9\end{array}$ & 119.2 & 12.8 & 9.19 \\
\hline & & 20 & $\begin{array}{l}19.18, \underline{41.09}, 24.67,20.51 \\
20.49,19.36,21.02,18.87 \\
20.91,23.94\end{array}$ & 20.99 & 9.70 & 1.56 \\
\hline
\end{tabular}

${ }^{a}$ Correlation coefficient. ${ }^{b}$ Standards were injected for calibration and as samples. ${ }^{\mathbf{c}}$ Results which are underlined were rejected by the $\mathbf{Q}$ test and not used for subsequent calculation of mean values, RSD or confidence intervals. ${ }^{d}$ Confidence interval.

trial and error. With the incorporation of a flow-injection dilution system, the sample could be diluted on-line for further measurements. Examples of dilution based on flow injection include zone sampling [9], variable volume injection [10], variable dispersion [11] and confluence dilution [12]. The concentration could then be calculated from the normal calibration curve already obtained and fitted by the computer, together with the relevant dispersion information.

Reducing the flow rate or introducing a mixing coil or chamber broadens the peaks which allows more data points to be collected on the rise portion of the peak. However, reducing the flow rate to the nebulizer can produce 
noise. Placing a mixing coil or chamber before the nebulizer increases the peak widths and so the slope of the peak-width calibration [1].

\section{Conclusion}

The approximation that the nebulizer behaves as a single, well-stirred tank breaks down for high concentrations, giving rise to significant deviation from the linear relationship predicted on the basis of this model. A more accurate curve fit may be obtained by using a cubic function and the results so obtained can be used to calculate dilution factors to allow further measurements within the most accurate concentration range. The peak-width method is limited by both the reproducibility of the absorbance/time profiles and the data acquisition rate.

The authors thank the Trustees of the Analytical Chemistry Trust Fund of the Royal Society of Chemistry for the award of an SAC Research Studentship.

\section{REFERENCES}

1 J. F. Tyson, Analyst (London), 109 (1984) 319.

2 J. F. Tyson and A. B. Idris, Analyst (London), 106 (1981) 1125.

3 K. K. Stewart and A. G. Rosenfeld, Anal. Chem., 54 (1982) 2368.

4 H. L. Pardue and B. Fields, Anal. Chim. Acta, 124 (1981) 39.

5 H. L. Pardue and B. Fields, Anal. Chim. Acta, 124 (1981) 65.

6 J. R. Hall, Notes on Alphastar-2 Atomic Absorption Curve Correction, Baird-Atomic, 1982.

7 A. R. Miller, BASIC Programs for Scientists and Engineers, Sybex, Berkeley, 1981.

8 J. C. Miller and J. N. Miller, Statistics for Analytical Chemistry, Ellis Horwood, Chichester, 1984.

9 B. F. Reis, A. O. Jacintho, J. Mortatti, F. J. Krug, E. A. G. Zagatto, H. Bergamin F and L. C. R. Pessenda, Anal. Chim. Acta, 123 (1981) 221.

10 J. F. Tyson, J. M. H. Appleton and A. B. Idris, Analyst (London), 108 (1983) 153.

11 J. F. Tyson, C. E. Adeeyinwo, J. M. H. Appleton, S. R. Bysouth, A. B. Idris and L. L. Sarkissian, Analyst (London), 110 (1985) 487.

12 E. A. G. Zagatto, F. J. Krug, H. Bergamin F, S. S. Jфrgensen and B. F. Reis, Anal. Chim. Acta, 104 (1979) 279. 